\title{
Effective enhancement of Pseudomonas stutzeri D-phenylglycine aminotransferase functional expression in Pichia pastoris by co-expressing Escherichia coli GroEL-GroES
}

Kanidtha Jariyachawalid ${ }^{1,3}$, Poramaet Laowanapiban², Vithaya Meevootisom²,3 and Suthep Wiyakrutta $2,3^{*}$

\begin{abstract}
Background: D-phenylglycine aminotransferase (D-PhgAT) of Pseudomonas stutzeri ST-201 catalyzes the reversible stereo-inverting transamination potentially useful in the application for synthesis of D-phenylglycine and D-4-hydroxyphenylglycine using L-glutamate as a low cost amino donor substrate in one single step. The enzyme is a relatively hydrophobic homodimeric intracellular protein difficult to express in the soluble functionally active form. Over-expression of the dpgA gene in E. coli resulted in the majority of the D-PhgAT aggregated into insoluble inclusion bodies that failed to be re-natured. Expression in Pichia pastoris was explored as an alternative route for high level production of the D-PhgAT.
\end{abstract}

Results: Intracellular expression of the codon-optimized synthetic $d p g A$ gene under the $P_{A O X}$ promoter in P. pastoris resulted in inactive D-PhgAT associated with insoluble cellular fraction and very low level of D-PhgAT activity in the soluble fraction. Manipulation of culture conditions such as addition of sorbitol to induce intracellular accumulation of osmolytes, addition of benzyl alcohol to induce chaperone expression, or lowering incubation temperature to slow down protein expression and folding rates all failed to increase the active D-PhgAT yield. Co-expression of E. coli chaperonins GroEL-GroES with the D-PhgAT dramatically improved the soluble active enzyme production. Increasing gene dosage of both the $d p g A$ and those of the chaperones further increased functional D-PhgAT yield up to 14400-fold higher than when the dpgA was expressed alone. Optimization of cultivation condition further increased D-PhgAT activity yield from the best co-expressing strain by 1.2-fold.

Conclusions: This is the first report on the use of bacterial chaperones co-expressions to enhance functional intracellular expression of bacterial enzyme in P. pastoris. Only two bacterial chaperone genes groEL and groES were sufficient for dramatic enhancement of functionally active D-PhgAT expression in this yeast. With the optimized gene dosage and chaperone combinations, P. pastoris can be attractive for intracellular expression of bacterial proteins since it can grow to a very high cell density which is translated into the higher volumetric product yield than the E. coli or other bacterial systems.

\footnotetext{
* Correspondence: suthep.wiy@mahidol.ac.th

${ }^{2}$ Department of Microbiology, Faculty of Science, Mahidol University, Rama 6

Road, Bangkok 10400, Thailand

${ }^{3}$ Center of Excellent for Agricultural Biotechnology: (AG-BIO/PERDO-CHE),

Bangkok, Thailand

Full list of author information is available at the end of the article
} 


\section{Background}

The D-phenylglycine aminotransferase (D-PhgAT) from a soil bacterium Pseudomonas stutzeri ST-201 [1], catalyzes the reversible transamination specific for D-phenylglycine or D-4-hydroxyphenylglycine in which 2-oxoglutarate is an amino-group acceptor that are converted into benzoylformate or 4-hydroxybenzoylformate and L-glutamate (Figure 1). Both D-phenylglycine and D-4-hydroxyphenylglycine are important side chain moieties in high demand for production of semisynthetic penicillin and cephalosporin antibiotics such as ampicillin, amoxicillin, cephalexine and cephadroxyl. Currently, D-phenylglycine and D-4-hydroxyphenylglycine are industrially produced by a process using two enzymes, the hydantoinase and carbamoylase [2]. However, the reaction rates are low since the solubilities of the substrates, (D,L) phenylhydantoin and (D,L)-4-hydroxyphenylhydantoin, are very poor. Alternatively, a single-step enzymatic synthesis using a D-amino acid aminotransferase is possible. But known D-amino acid aminotransferases have very low transamination activity towards D-phenylglycine [3] and they accept only D-amino acids as the amino-group donors. Due to the high cost of D-amino acids (such as D-alanine, D-glutamic acid), their direct application as amino-group donors is impractical. Using an L-amino acid (such as L-alanine or L-glutamic acid) together with an amino acid racemase to convert it to the corresponding D-amino acid to serve as the amino-group donor for the D-amino acid aminotransferase will increase the production cost. Additionally, the racemase may interfere with the transamination reaction. By contrast, with the D-PhgAT, due to its characteristic "stereo-inverting" transamination activity, a low cost substrate L-glutamic acid can be used as an amino-group donor for the synthesis of enantiomerically pure D-phenylglycine or D-4-hydroxyphenylglycine in a single transamination step without the need for any amino acid racemase [1].

Before enzymatic synthesis of D-phenylglycine and D4-hydroxyphenylglycine using D-PhgAT can be further developed, a large supply of the enzyme should be established. Initially, the conventional method using commercially available gene expression systems for overproduction of the D-PhgAT in E. coli resulted in the formation of inclusion body and very low amount of the soluble functional enzyme was obtained [unpublished observations]. The attempt to solubilize the insoluble enzyme aggregates and refold the protein, using a published method [4], to the functional D-PhgAT was not successful.

It is well-known that Pichia pastoris protein expression system offers various advantages [5-7] including the success in high level production of a variety of heterologous proteins both intra- and extracellularly, the ability of the host to grow to very high cell density using simple culture media, and the availability of powerful genetic manipulation techniques. Several approaches for improving the solubility and expression level of recombinant protein in $P$. pastoris have been reported, for instance, low-temperature expression [8,9], adjusting of media composition [10,11], modifying the host strains $[12,13]$, fine-tuned gene expression by generating promoter mutants [14], rational sitedirected mutagenesis $[15,16]$, directed evolution $[17,18]$, translational fusion proteins [19-22], co-expression of chaperones [23-26], codon optimization [27,28] and creating the multiple gene copy number [29-31]. The beneficial characteristics and the documented successful applications encouraged us to exploit the $P$. pastoris protein expression system for production of soluble active D-PhgAT at high yield.

\section{Results}

Intracellular expression of D-PhgAT in P. pastoris KM71

Levels of D-PhgAT production from $P$. pastoris KM71 clones harboring 3 copies of wild-type and codonoptimized $d p g A$ genes under the $A O X 1$ promoter were compared. Expression from the codon-optimized $d p g A$ gene yielded high amount of D-PhgAT protein (Figure 2A) with low level of D-PhgAT activity (Table 1, strain KM_AT3). By contrast, expression from wild-type $d p g A$ gene resulted in much lower amount of D-PhgAT protein and no D-PhgAT activity was detectable.

The codon-optimized synthetic $\operatorname{dpg} A$ gene under the control of the $A O X 1$ promoter of the pPIC3.5 K plasmid was integrated into the HIS4 locus on the chromosome of the $P$. pastoris KM71 host. The clone harboring 3 copies of the $d p g A$ gene was induced with $0.5 \%$ methanol for gene expression at $30^{\circ} \mathrm{C}$ for $144 \mathrm{~h}$ to determine the $\mathrm{D}$ PhgAT yield and the optimal time for product harvesting. The D-PhgAT was strongly expressed constituting up to $30 \%$ of total cellular proteins after $24 \mathrm{~h}$ of induction and remained at this level until $144 \mathrm{~h}$ (Figure 2B). However,

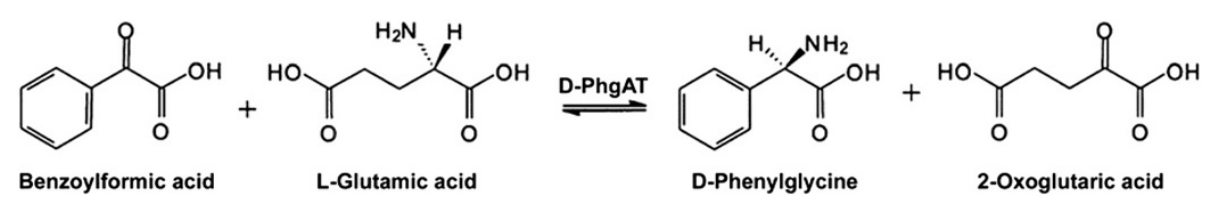

Figure 1 Stereo-inverting aminotransferase reaction catalyzed by D-PhgAT from Pseudomanas stutzeri ST-201. The enzyme reversibly transfers the amino group between L-glutamic acid and D-phenylglycine which have opposite stereochemistry. 


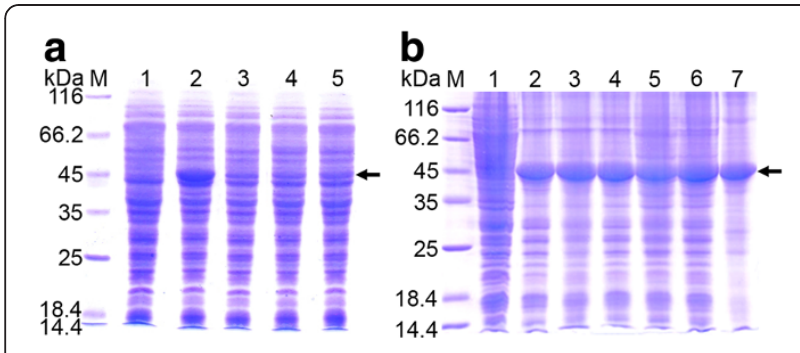

Figure 2 Expression of D-PhgAT in P. pastoris KM71. SDS-PAGE analysis of total cellular proteins of (a) P. pastoris KM71 expressing wild-type and codon-optimized $\operatorname{dpg} A$ genes under the control of AOX1 promoter at $30^{\circ} \mathrm{C}$ for $24 \mathrm{~h}$. Lane $\mathrm{M}$, molecular mass markers; Lane 1, P. pastoris KM71 harboring the parent vector pPIC3.5 K; Lane 2, P. pastoris strain KM_AT3 (see Table 1) expressing D-PhgAT from the codon-optimized dpgA gene; Lane 3-5, three P. pastoris clones expressing D-PhgAT from the wild-type $d p g A$ gene. (b) Lane 2-7, P. pastoris KM_AT3 after induction at $30^{\circ} \mathrm{C}$ for $24,48,72,96,120$ and $144 \mathrm{~h}$, respectively. The arrow indicates protein bands of the D-PhgAT (45 kDa)

majority of the expressed D-PhgAT associated with the insoluble cellular fraction (Figure 3) as inactive enzyme. Soluble protein fraction was found to contain D-PhgAT enzymatic activity at $0.0054 \mathrm{U} \cdot \mathrm{mg}^{-1}$ (Table 1). Several strategies known to promote native folding of the overexpressed proteins including lower temperature, increased intracellular concentrations of osmolytes and molecular chaperones [32] were attempted in this study. By using $0.5 \mathrm{M}$ sorbitol, 0.4 to $4 \mathrm{mM}$ benzyl alcohol, and $20^{\circ} \mathrm{C}$ incubation temperature; the yield of soluble active D-PhgAT was not significantly enhanced as judged from the intensity of protein bands (Figure 4).

\section{Co-expression of GroEL-GroES chaperones with D-PhgAT in $P$. pastoris KM71}

The pAO815 plasmid containing the $d p g A$ gene under the control of $A O X 1$ promoter and the groEL and groES genes each under the control of an $A O X 1$ promoter (pAO_DPhgAT_AOX_ELS) or a GAP promoter (pAO_D-PhgAT_GAP_ELS) were constructed [see Additional file 1]. After transformation and gene integration into the $P$. pastoris KM71 chromosome, it was found that co-expression of GroEL-GroES molecular chaperones with D-PhgAT at $30^{\circ} \mathrm{C}$ yielded functionally active enzyme with the highest activity at $24 \mathrm{~h}$ after induction. Clone harboring PAO_D-PhgAT_GAP_ELS yielded slightly higher D-PhgAT activity than that with PAO_D-PhgAT_AOX_ELS (Figure 5). Noticeably, DPhgAT activity declined after $48 \mathrm{~h}$ and slightly increased after $72 \mathrm{~h}$. Viable cell count showed the decrease in number of viable cells at $48 \mathrm{~h}$ and increase at $72 \mathrm{~h}$ correlated well with the D-PhgAT activity profile. SDS-PAGE analysis of cellular proteins revealed substantial amounts of D-PhgAT protein in the soluble protein fractions concomitant with its absence from the insoluble fractions (Figure 6).

\section{Expression of multiple copies of $\operatorname{dpg} A$, groEL and groES genes in P. pastoris KM71}

The $P$. pastoris KM71 chromosomally harboring at the HIS4 locus 3 copies of the $d p g A$ gene under the control of $P_{A O X 1}$ after transformation with pPIC3.5K_D-PhgAT plasmid was used as the host for co-expression with multiple copies of the groEL and groES genes. The pPICZ_26S rDNA_GAP_GroELS [see Additional file 2] was constructed to express the $P_{G A P}$ groEL and $P_{G A P}$ groES that could be integrated in multiple copies at either the $5^{\prime} A O X 1$ or the 26S rDNA sites of the Pichia chromosome. After screening the transformants on YPD plates containing zeocin, two clones from $5^{\prime} A O X 1$ integration and two clones from $26 \mathrm{~S}$ rDNA integration experiments showed resistance to $5000 \mu \mathrm{g} \cdot \mathrm{mL}^{-1}$ of zeocin. Quantitative real time PCR analysis of gene copy number revealed that clones obtained from $5^{\prime} A O X 1$ integration contained 3 and 4 copies, while clones from 26S rDNA integration contained 2 and 10 copies of the groEL-groES genes, repectively. D-PhgAT expressions of these clones were performed at $30^{\circ} \mathrm{C}$ in

Table 1 Copy number of $d p g A$ and groEL-groES genes and D-PhgAT activity of different $P$. pastoris clones

\begin{tabular}{|c|c|c|c|c|c|c|c|}
\hline \multirow[t]{2}{*}{ Strain name } & \multirow[t]{2}{*}{ Host strain } & \multirow[t]{2}{*}{ Integrated plasmid } & \multirow{2}{*}{$\begin{array}{l}\text { Integration } \\
\text { site }\end{array}$} & \multicolumn{2}{|c|}{ Copy number } & \multirow{2}{*}{$\begin{array}{c}\text { Specific } \\
\text { D-PhgAT activity } \\
{\left[\mathrm{U} \cdot \mathrm{mg}^{-1}\right]^{\mathrm{a}}}\end{array}$} & \multirow{2}{*}{$\begin{array}{c}\text { Volumetric } \\
\text { D-PhgAT activit } \\
{\left[\mathrm{U} \cdot \mathrm{L}^{-1}\right]^{\mathrm{b}}}\end{array}$} \\
\hline & & & & $\operatorname{dpg} A$ & groEL-groES & & \\
\hline \multirow[t]{2}{*}{ KM_AT3 } & KM71 & pPIC3.5K_ & HIS4 & 3 & 0 & 0.0054 & 2.9 \\
\hline & & D-PhgAT & & & & & \\
\hline \multirow[t]{2}{*}{$\overline{\text { KM_AT1_ELS1 }}$} & KM71 & $\mathrm{pAO}_{-}$ & HIS4 & 1 & 1 & 12.6 & 7531 \\
\hline & & D-PhgAT_GAP_ELS & & & & & \\
\hline KM_AT3_ELS3 & KM71_D-PhgAT & pPICZ_26S_GAP_ELS & $5^{\prime} A O X 1$ & 3 & 3 & 23.3 & 14558 \\
\hline KM_AT3_ELS4 & & & $5^{\prime} A O X 1$ & 3 & 4 & 45.3 & 34809 \\
\hline KM_AT3_ELS2 & & & $26 \mathrm{~S}$ rDNA & 3 & 2 & 14.6 & 11027 \\
\hline KM_AT3_ELS10 & & & 265 rDNA & 3 & 10 & 60.1 & 41730 \\
\hline
\end{tabular}

Cells were cultured at $30^{\circ} \mathrm{C}$.

${ }^{a}$ Specific activity was calculated as unit of D-PhgAT activity per mg of soluble cellular protein.

${ }^{\mathrm{b}}$ Volumetric activity was calculated as unit of D-PhgAT activity obtained per liter of $P$. pastoris culture. 


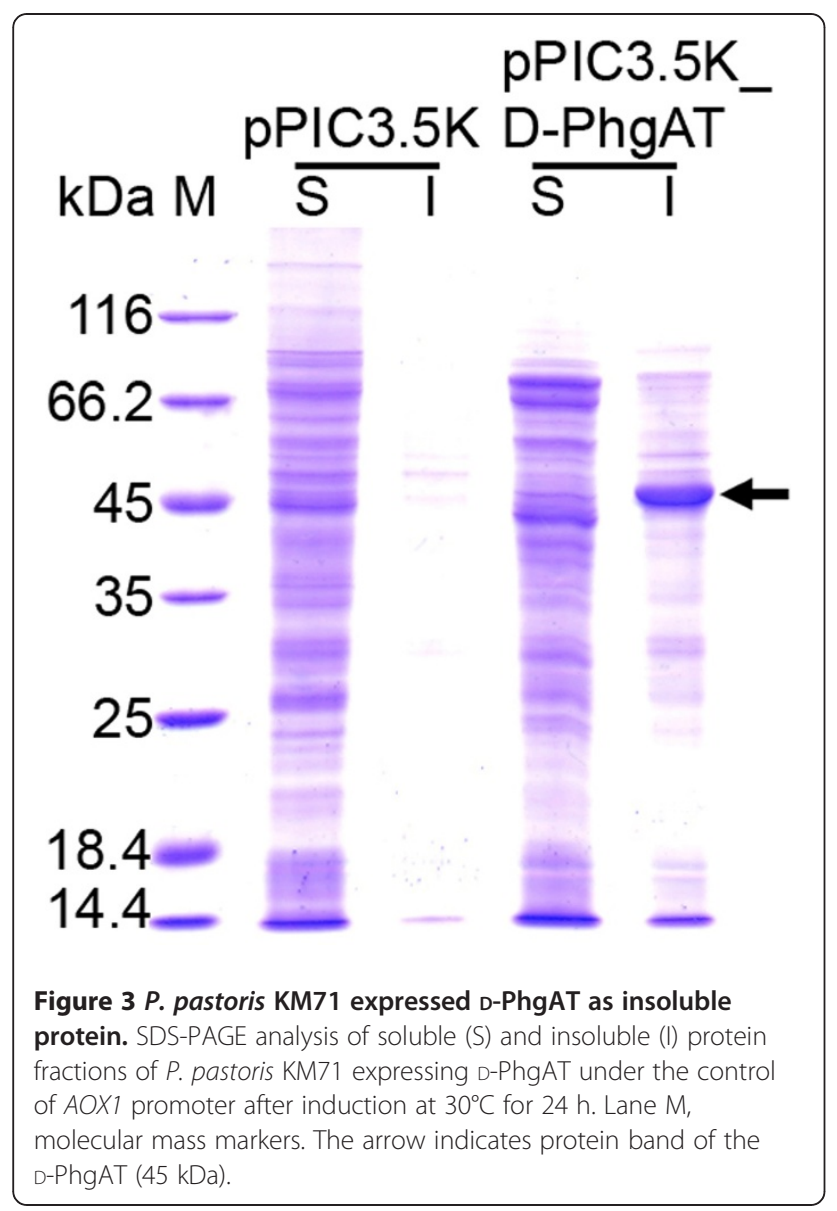

culture medium containing $0.5 \%$ methanol for $24 \mathrm{~h}$. Compared with strain containing single copies of the $\operatorname{dpgA}$ and groEL-groES genes (KM_AT1_ELS1), clones with multiple copies yielded approximately 1.5 times (KM_AT3_ELS2) to 5.5 times (KM_AT3_ELS10) more of D-PhgAT volumetric activity. The D-PhgAT volumetric activity from clone coexpressing 10 copies of groEL-groES was 14400 times higher than the clone expressing $d p g A$ alone (Table 1). SDS-PAGE analyses comparing D-PhgAT expressions from different $P$. pastoris KM71 strains constructed in the present study are shown in Figure 7. The amounts of DPhgAT protein in the soluble fractions of cellular protein extracts correlated well with the D-PhgAT enzymatic activity summarized in Table 1. And less amounts of insoluble D-PhgAT protein were formed as the copy number of the co-expressing groEL-groES genes increased.

\section{Effect of cultivation conditions on soluble active D-PhgAT} yield in P. pastoris KM_AT3_ELS10

As the highest yield of soluble active D-PhgAT was obtained in the P. pastoris KM_AT3_ELS10 which contained 3 copies of the $d p g A$ gene and 10 copies of the groEL-groES genes, optimization of the cultivation conditions was done on this final co-expressing strain to see if the active D-PhgAT yield could be further increased. The KM_AT3_ELS10 was cultivated under various conditions known to promote the native protein folding including addition of $0.5 \mathrm{M}$ sorbitol, $0.4 \mathrm{mM}$ benzyl alcohol and lowering the incubation temperatures to $25^{\circ} \mathrm{C}$ and $20^{\circ} \mathrm{C}$. At $24 \mathrm{~h}$ of induction with $0.5 \%$ methanol, cells were collected and the levels of D-PhgAT protein and enzymatic activity were analyzed. As shown in Table 2, lowering the cultivation temperature from $30^{\circ} \mathrm{C}$ to $25^{\circ} \mathrm{C}$ resulted in higher D-PhgAT activity yields but further decreasing the temperature to $20^{\circ} \mathrm{C}$ deteriorated the activity yields to lower than those at $30^{\circ} \mathrm{C}$. Addition of $0.5 \mathrm{M}$ sorbitol or $0.4 \mathrm{mM}$ benzyl alcohol or both,

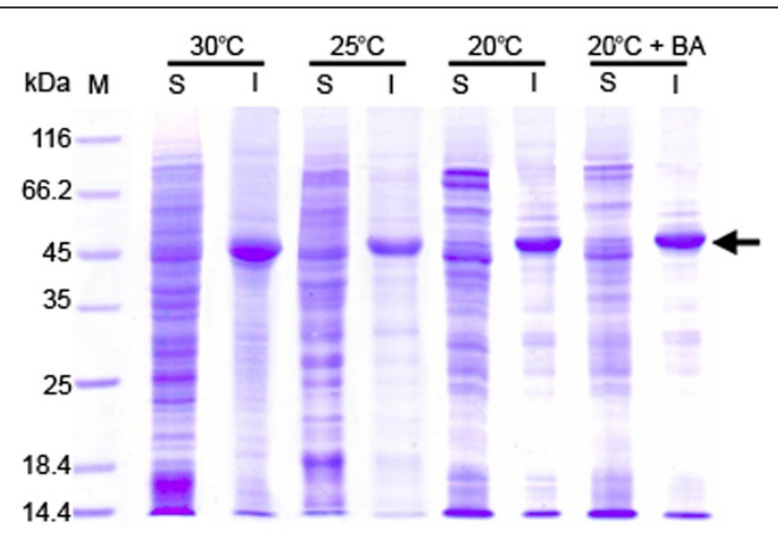

Figure 4 Effect of temperature and benzyl alcohol (BA) on soluble D-PhgAT production. SDS-PAGE analysis of soluble (S) and insoluble (I) protein fractions from $P$. pastoris KM71 expressing D-PhgAT under the control of $A O X 1$ promoter after induction for $24 \mathrm{~h}$ at $30^{\circ} \mathrm{C}, 25^{\circ} \mathrm{C}$, and at $20^{\circ} \mathrm{C}$ without and with $0.4 \mathrm{mM}$ benzyl alcohol added to the culture. Lane $\mathrm{M}$, molecular mass markers. The arrow indicates protein bands of D-PhgAT. 


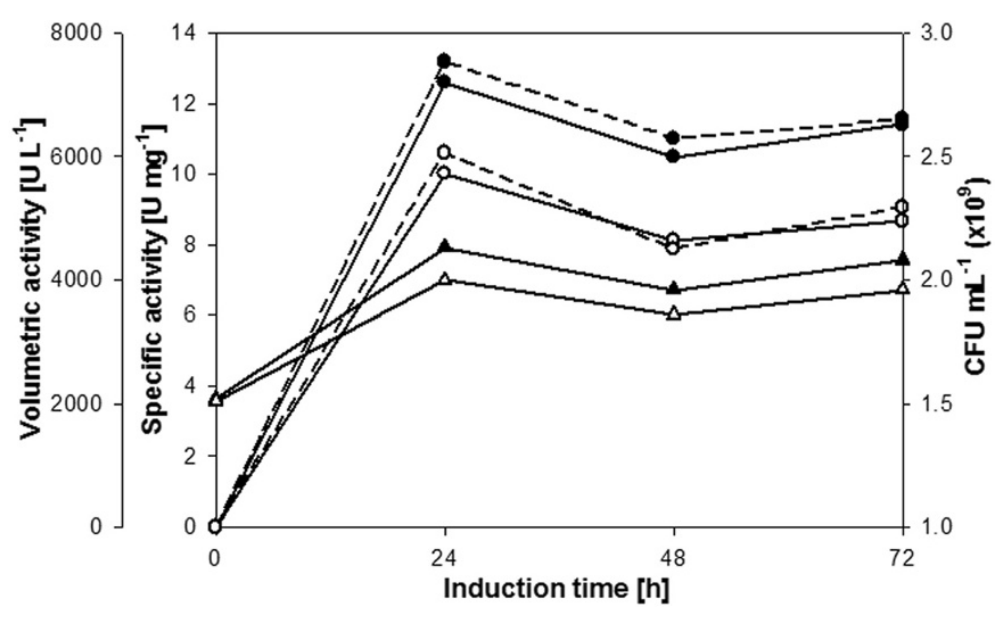

Figure 5 D-PhgAT activity from P. pastoris KM71 co-expressing groEL and groES with dpgA. D-PhgAT activity in cell extract and viable cell counts of P. pastoris KM71 integrated with PAO_D-PhgAT_AOX_ELS plasmid (white circle, white triangle) or pAO_D-PhgAT_GAP_ELS (filled circle, filled triangle) during induction with $0.5 \%$ methanol at $30^{\circ} \mathrm{C}$ for $72 \mathrm{~h}$. Solid line, specific activity; dash line, volumetric activity; please see Table 1 for definitions.

impaired the D-PhgAT activity yields at all three temperatures tested. The strongest negative effects were observed when both additives were present. The best specific and volumetric D-PhgAT activity yields of 72.7 $\mathrm{U} \cdot \mathrm{mg}^{-1}$ and $50512 \mathrm{U} \cdot \mathrm{L}^{-1}$, respectively, were obtained when the cultivation temperature was $25^{\circ} \mathrm{C}$ and without additives. SDS-PAGE analysis of proteins in the soluble and insoluble protein fractions of cells cultivated under the above conditions showed the amount of D-PhgAT protein

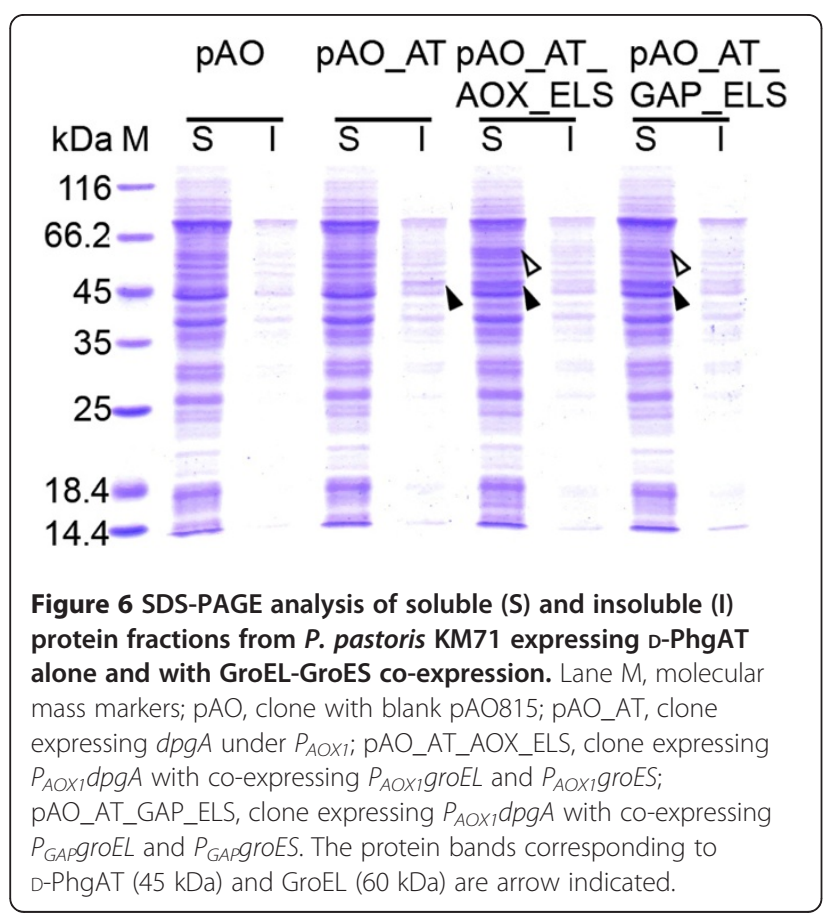

(Figure 8) in good agreement with the D-PhgAT activity detected (Table 2).

\section{Purification of recombinant D-PhgAT using immobilized metal ion affinity chromatography}

The D-PhgAT was purified from the clarified cell lysates by His tag-mediated affinity chromatography. Protein elution profile during purification is shown in Figure 9A. The unbound proteins were washed out with $45 \mathrm{~mL}$ of binding buffer and peak of unrelated proteins was eluted with early imidazole gradient. The D-PhgAT was eluted in a large symmetrical peak well-separated from other host proteins at around $35 \mathrm{mM}$ imidazole. SDS-PAGE analysis of active fractions collected from this peak showed that the DPhgAT was purified to near homogeneity (Figure 9B). The process brought about 5.2-fold purification and 76.6\% yield in one single step. After concentration, the enzyme solution consisting of pure D-PhgAT (Figure 9C) had a specific activity of $888.6 \mathrm{U} \cdot \mathrm{mg}^{-1}$.

\section{Discussion}

The methylotrophic yeast Pichia pastoris has been developed for heterologous protein expression offering several advantages over other eukaryotic or prokaryotic systems including the high levels expression of intracellular and secreted proteins in the range of grams per liter using the strong inducible $P_{A O X}$ promoter or the strong constitutive $P_{G A P}$ promoter, the ability to grow at high cell-density, the simple scale up and well-developed fermentation processes [8,33-35]. Since $P$. pastoris has eukaryotic posttranslational modification machinery which can process the expressed protein similar to higher eukaryotes, it is usually 


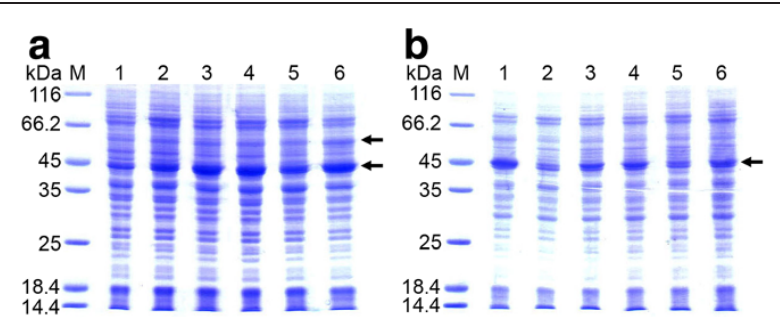

Figure 7 Comparison of D-PhgAT expressions from $P$. pastoris KM71 strains carrying different copy numbers of $d p g A$ and groEL-groES genes. SDS-PAGE analysis of soluble (a) and insoluble (b) fractions from 6 recombinant strains. Lane M, molecular mass markers; Lane 1, strain KM_AT3; Lane 2; strain KM_AT1_ELS1; Lane 3-6; strains KM_AT3_ELS3, KM_AT3_ELS4, KM_AT3_ELS2, KM_AT3_ELS10, respectively. Please see Table 1 for details of each strain. The protein bands corresponding to D-PhgAT (45 kDa) and GroEL (60 kDa) are arrow indicated.

a system of choice for expression of eukaryotic proteins which require proper posttranslational modifications for their functions. Thus, so far there are only a few reports that exploit the benefits of the $P$. pastoris system for the high level expression of bacterial proteins, especially the intracellular ones.

In our case, the Pseudomonas D-PhgAT which is a relatively hydrophobic homodimeric intracellular enzyme [1] has been shown to be difficult to express in the regular E. coli expression system. We thus explored the possibility of using the $P$. pastoris system as an alternative approach for expressing this problematic enzyme. Initially, the $d p g A$ gene encoding the D-PhgAT was expressed under the strong inducible promoter $A O X 1$ both intracellularly, and extracellularly by fusion with the alpha-factor signal peptide. The extracellular expression resulted in no D-PhgAT protein or enzymatic activity, neither in culture medium nor in cell extract (data not shown). For intracellular expression, the D-PhgAT was highly produced at up to $30 \%$ of total cellular proteins but as the inactive enzyme in the insoluble cellular fraction. Noticeably, very low level of DPhgAT activity could be detected in the cell extracts indicating that functional expression of D-PhgAT in this host is possible which encouraged us to further pursue system optimization. Addition of sorbitol to the culture medium at a high concentration $(0.5 \mathrm{M})$ to force the Pichia cells to accumulate viscous intracellular osmolytes (such as glycerol) which slow down the rates of protein structure acquisition and might enhance native folding of the enzyme [32,36,37] yielded no detectable D-PhgAT activity. The reason for this failure may be because intracellular glycerol accumulation in response to osmotic stress might repress the $A O X 1$ promoter in spite of the presence of methanol as an inducer [38-40]. Likewise, addition of benzyl alcohol at $0.4-4 \mathrm{mM}$ as a membrane fluidizing heat shock response inducing agent for inducing the synthesis of intracellular molecular chaperones that would assist protein folding [32,41]

Table 2 Effects of cultivation conditions on D-PhgAT yield from P. pastoris strain KM_AT3_ELS10

\begin{tabular}{|c|c|c|c|c|c|}
\hline \multicolumn{3}{|c|}{ Cultivation condition } & \multicolumn{3}{|c|}{ D-PhgAT activity } \\
\hline \multirow[t]{2}{*}{ Temperature } & \multicolumn{2}{|c|}{ Additive } & \multirow{2}{*}{$\begin{array}{l}\text { Specific } \\
\text { activity } \\
{\left[\mathrm{U} \cdot \mathrm{mg}^{-1}\right]^{\mathrm{a}}}\end{array}$} & \multirow{2}{*}{$\begin{array}{c}\text { Volumetric } \\
\text { activity } \\
{\left[\mathrm{U} \cdot \mathrm{L}^{-1}\right]^{\mathrm{b}}}\end{array}$} & \multirow{2}{*}{$\begin{array}{c}\text { Volumetric } \\
\text { productivity } \\
{\left[\mathrm{U} \cdot \mathrm{L}^{-1} \cdot \mathrm{h}^{-1}\right]}\end{array}$} \\
\hline & 0.5 M Sorbitol & $0.4 \mathrm{mM}$ Benzyl alcohol & & & \\
\hline \multirow[t]{4}{*}{$30^{\circ} \mathrm{C}$} & - & - & 60.1 & 41730 & 1738.75 \\
\hline & + & - & 52.3 & 36526 & 1521.92 \\
\hline & - & + & 52.7 & 36616 & 1525.67 \\
\hline & + & + & 51.1 & 35504 & 1479.33 \\
\hline \multirow[t]{4}{*}{$25^{\circ} \mathrm{C}$} & - & - & 72.7 & 50512 & 2104.67 \\
\hline & + & - & 70.1 & 48663 & 2027.63 \\
\hline & - & + & 72.0 & 50165 & 2090.21 \\
\hline & + & + & 67.1 & 46602 & 1941.75 \\
\hline \multirow[t]{4}{*}{$20^{\circ} \mathrm{C}$} & - & - & 58.9 & 40810 & 1700.42 \\
\hline & + & - & 53.1 & 36920 & 1538.33 \\
\hline & - & + & 58.3 & 40830 & 1701.25 \\
\hline & + & + & 51.7 & 35722 & 1488.42 \\
\hline
\end{tabular}




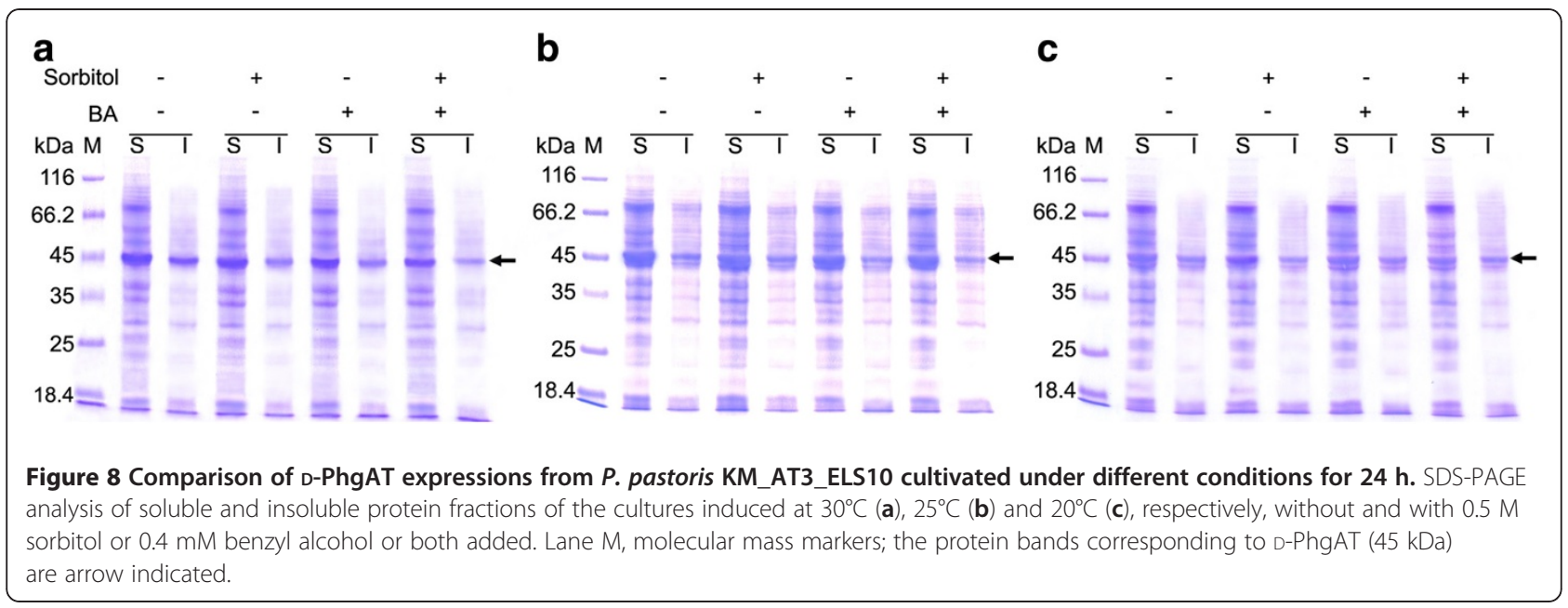

was found to be ineffective and all the expressed DPhgAT was nonfunctional and associated with insoluble cellular fraction. Decreasing the incubation temperature to $20^{\circ} \mathrm{C}$ to slow down the rates of protein translation and folding could not increase the formation of soluble active D-PhgAT.

As all the simple approaches mentioned above failed, we attempted a more sophisticated method by co-expression

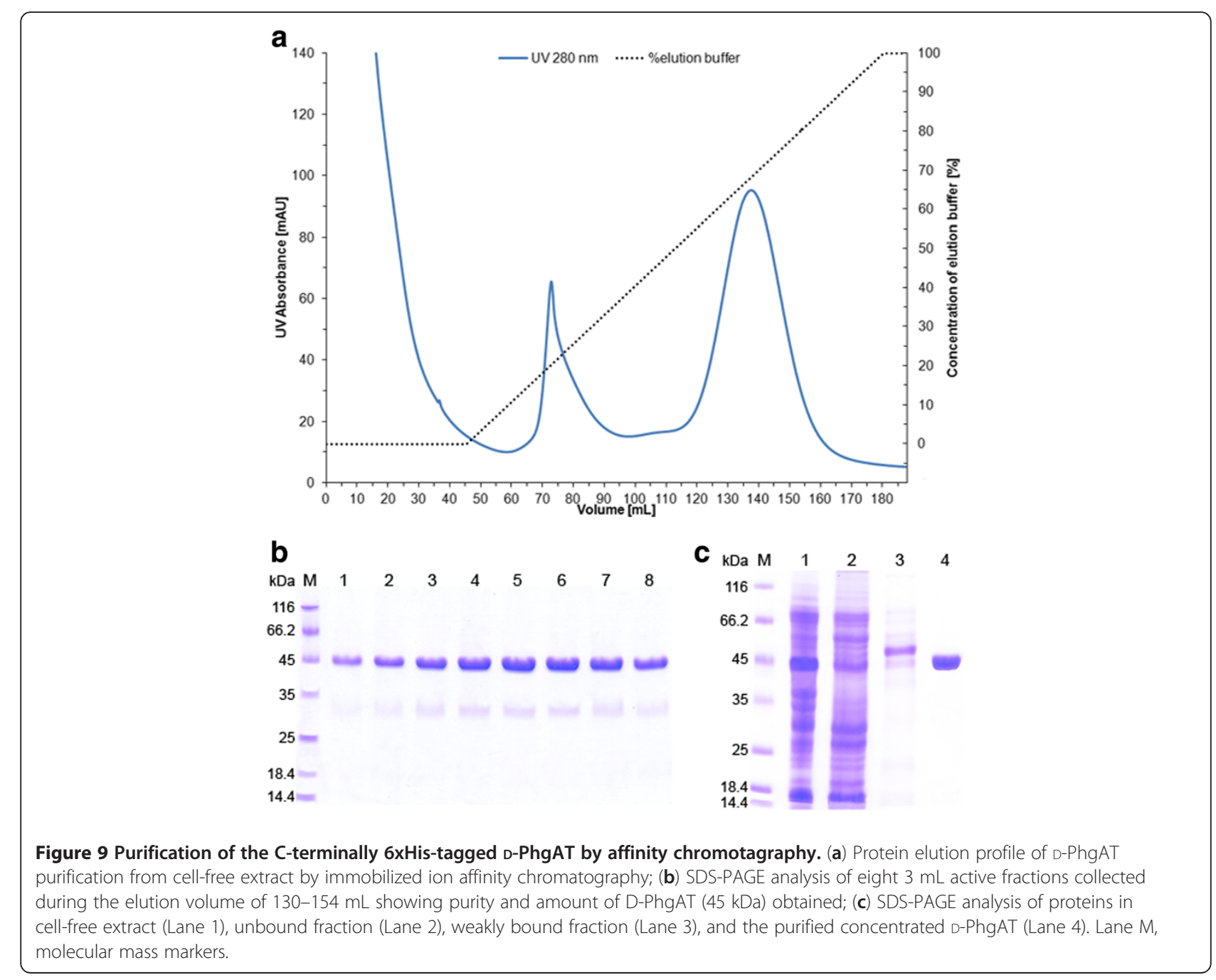


with molecular chaperones. D-PhgAT is an enzyme of a Gram-negative bacterium. We hypothesized that if we coexpressed functional $E$. coli chaperones (whose expression plasmids are commercially available) in $P$. pastoris the chaperones would assist native folding of the D-PhgAT. Without codon optimization, two genes encoding the $E$. coli GroEL-GroES chaperonin system were co-expressed intracellularly under the strong inducible $P_{A O X 1}$ or the strong constitutive $P_{G A P}$ with the $P_{A O X 1} \operatorname{dpgA}$, each as a single copy gene, in $P$. pastoris. Interestingly, substantial amount of soluble D-PhgAT was produced and ca 2600fold increased in volumetric activity could be measured, compared with the system without chaperone coexpression (Figures 4, 6 and Table 1). Co-expression of groEL and groES under the constitutive promoter $P_{G A P}$ yielded slightly more active D-PhgAT than with the inducible promoter $P_{A O X 1}$ suggesting that constitutive expression of molecular chaperones prior to the strong induction of D-PhgAT expression could be more effective in promoting native protein folding. Increasing gene dosage of the $\operatorname{dpg} A$ and those of the groEL and groES progressively increased the D-PhgAT activity yield (Table 1). It was obvious that chaperones gene were required in a higher copy numbers than the $d p g A$ gene. The highest gene dosage that could be integrated into the chromosome of the $P$. pastoris host in the present study was 3 copies of the $d p g A$ and 10 copies each of the groEL and groES which could increase the D-PhgAT yield up to 14400-fold higher than with 3 copies of the $\operatorname{dpg} A$ expressed without chaperone co-expression. It is likely that gene dosage for maximum D-PhgAT yield for this system had not been reached and yet remains to be determined. Co-expression of additional chaperone(s) in various combinations should also be investigated.

\section{Conclusions}

To the best of our knowledge, this is the first report on the use of bacterial chaperone (specifically the E. coli GroEL-GroES) co-expression to enhance functional expression of a difficult-to-express bacterial enzyme in $P$. pastoris. The interesting point is that only two bacterial chaperone genes were sufficient to dramatically enhance functional expression of a bacterial enzyme in this host. The $P$. pastoris system is attractive for intracellular expression of bacterial proteins because the organism can be cultured in a very high cell density. With the optimized gene expression this could be translated into a higher volumetric product yield than the bacterial systems such as E. coli. Additionally, compared with plasmid-based expression in bacteria, chromosomally integrated recombinant gene in P. pastoris can be far more stably expressed in continuous and large-scale fermentation process without the need for antibiotic selection [6].

\section{Methods}

Strains, plasmids, oligonucleotides, media, chemicals

The E. coli DH5 $\alpha$ and P. pastoris KM71 were obtained from Novagen (Madison, WI, USA) and Invitrogen (San Diego, CA, USA), respectively. The Pichia expression plasmids pPIC3.5 K, pAO815, pGAPZ B and pPICZ B were purchased from Invitrogen. The pGro7 was purchased from Takara Bio Inc (Japan). The pPICZ_26S rDNA was constructed and provided by Prof. W. Panbangred (Mahidol University, Thailand). The pBPL-ph plasmid harboring the wild-type $d p g A$ gene was obtained from our previous study [42]. The $d p g A$ gene was codonoptimized for expression in Pichia host, and synthesized by GenScript (Piscataway, NJ, USA) [see Additional file 3]. Primers for gene amplification and real-time PCR are shown in Table 3. Restriction endonucleases, DNA polymerase and T4 DNA ligase were supplied by New England Biolabs (Ipswich, MA, USA). Culture media for bacteria and yeast cultivation: Luria-Bertani (LB), Yeast ExtractPeptone-Dextrose (YPD), buffered complex glycerol (BMGY), buffered complex methanol (BMMY) and Minimal Dextrose (MD) were from Becton, Dickinson \& Co. (NJ, USA). The antibiotics ampicillin and zeocin were from Bio Basic (Ontario, Canada) and Invitrogen, respectively. Methanol and all other chemicals were obtained from Sigma (St. Louis, MO, USA).

\section{Generation of Pichia pastoris strain expressing intracellularly recombinant $\mathrm{D}$-PhgAT}

Wild-type $\operatorname{dpgA}$ gene was amplified from the pBPLph plasmid using the $P f u$ DNA polymerase with the FwtdpgA and RwtdpgA primers containing BamHI and EcoRI sites, respectively. Cloning of the wildtype $\operatorname{dpg} A$ gene into the Pichia expression plasmid pPIC3.5K, transformation into $P$. pastoris KM71, and selection of integrant clones were performed in the same manners as for the $P$. pastoris codon-optimized synthetic $\operatorname{dpg} A$ gene described below.

The synthetic dpgA gene in the pUC57_D-PhgAT plasmid obtained from GenScript was PCR amplified using the $P f u$ DNA polymerase with the forward and reverse primers FdpgA_3.5 K and RdpgA_3.5 K (Table 3) having BamHI and EcoRI sites, respectively. The PCR product was digested and cloned into the corresponding sites of the Pichia expression vector pPIC3.5 K yielding the pPIC3.5K_D-PhgAT which was subsequently transformed into $E$. coli DH5 $\alpha$. The pPIC3.5K_D-PhgAT plasmid extracted from E. coli DH5 $\alpha$ was linearized with SalI and $10 \mu \mathrm{g}$ of the DNA was mixed with $80 \mu \mathrm{L}$ of competent $P$. pastoris KM71 cell suspension. Transformation by electroporation was carried out at $1.5 \mathrm{kV}, 25 \mu \mathrm{F}$ and $200 \Omega$ (Gene Pulser II (Bio-Rad). The transformants were selected on minimal dextrose (MD) without histidine 
Table 3 Primers used in PCR and DNA sequencing reactions. F: forward primer, R: reverse primer, underlined: restriction endonuclease site

\begin{tabular}{|c|c|c|}
\hline Name & Sequence $\left(5^{\prime}-3^{\prime}\right)$ & Application \\
\hline FwtdpgA & CGGGATCCACCATGTCGATCCTTAACG & Amplifying and cloning \\
\hline RwtdpgA & AGGAATTCTCATGATTGGTTTCCAGAC & \\
\hline FdpgA_3.5 K & CGGGATCCACCATGTCCATCCTGAACG & \\
\hline RdpgA_3.5 K & AGGAATTCTTAGCAGTGATGGTGAT & \\
\hline FdpgA_AO & GGAATTCACCATGTCCATCCTGAACGACTACAAGAG & \\
\hline RdpgA_AO & CAGGTCTCCAATTGTTAGCAGTGATGGTGATGGTGATG & \\
\hline FgroES_GAP & GGAATTCACCATGAATATTCGTCCATTGC & \\
\hline RgroES_GAP & GCTCTAGATTACGCTTCAACAATTGCCAG & \\
\hline FgroEL_GAP & GGAATTCACCATGGCAGCTAAAGACGTAAAATTCGGTAACG & \\
\hline RgroEL_GAP & GCTCTAGATTACATCATGCCGCCCATGCCACC & \\
\hline FgroES_AO & GGAATTCACCATGAATATTCGTCCATTGC & \\
\hline RgroES_AO & CAGGTCTCCAATTGTTACGCTTCAACAATTGCCAG & \\
\hline FgroEL_AO & GGAATTCACCATGGCAGCTAAAGACGTAAAATTCGGTAACG & \\
\hline RgroEL_AO & CAGGTCTCCAATTGTTACATCATGCCGCCCATGCCACC & \\
\hline F_ELS_PICZ & CCGCTCGAGTTTTGGTCATGCATGAGATC & \\
\hline R_ELS_PICZ & ATAGTTTAGCGGCCGCTTTTGAAGCTATGGTGTG & \\
\hline F_GroEL & TGTCCGTACCATGCTCTGAC & Copy number determination \\
\hline R_GroEL & CAGGTAGCCACGGTCGAAC & \\
\hline F_D-PhgAT & GССTGCTCCAGGTGTCTTGC & \\
\hline R_D-PhgAT & АСTGTCTAGCCAATTCAGCACC & \\
\hline F_Actin & AAAAGATCTGGCACCACACC & \\
\hline R_Actin & AGTGGTTCTACCGGAAGCG & \\
\hline $5^{\prime} A O \times 1$ & GACTGGTTCCAATTGACAAGC & DNA sequencing \\
\hline $3^{\prime} A O X 1$ & GCAAATGGCATTCTGACATCC & \\
\hline
\end{tabular}

(1.34\% YNB with ammonium sulphate without amino acids, $4 \times 10^{-5} \%$ biotin, and $2 \%$ dextrose) agar plates. Two $\mathrm{mL}$ of sterile water was spread over the $\mathrm{His}^{+}$ transformants on each MD plate to resuspend the transformants. Cell suspensions from all plates were pooled and transferred into a sterile, $50 \mathrm{~mL}$ conical centrifuge tube, and vortexed briefly for $5-10$ seconds. The cell density was determined using a spectrophotometer $\left(1 \mathrm{OD}_{600 \mathrm{~nm}}=5 \times 10^{7}\right.$ cells $\left.\cdot \mathrm{mL}^{-1}\right)$. The $10^{-5}$, $10^{-6}$ and $10^{-7}$ dilutions of the pooled transformants were prepared using sterile water and $200 \mu \mathrm{L}$ aliquots were plated on YPD agar containing Geneticin at final concentration of $250,500,750$ and $1000 \mu \mathrm{g} \cdot \mathrm{mL}^{-1}$. All plates were incubated at $30^{\circ} \mathrm{C}$ and examined daily to select for the strains containing multiple copies of the $d p g A$ gene. The integration of the $d p g A$ gene into the chromosome of selected Pichia transformants was verified by PCR using gene specific primers (FdpgA_3.5 K and RdpgA_3.5 K, Table 3). The verified clone with the highest D-PhgAT expression level as judged from the enzyme activity was subjected to DNA sequencing to check for the correctness of the integrated $d p g A$ gene before it was utilized in this study. Genomic DNA was isolated from the selected $P$. pastoris clones. The integrated DNA fragment containing the $\operatorname{dpg} A$ gene was amplified using the $5^{\prime}$ $A O X 1$ and $3^{\prime} A O X 1$ primers. The PCR product was subjected to DNA sequencing on both strands using the $5^{\prime} A O X 1$ and $3^{\prime} A O X 1$ as sequencing primers (Table 3).

\section{Construction of plasmids for co-expressing D-PhgAT with GroEL and GroES}

The $d p g A$ gene amplified from the pUC57_D-PhgAT plasmid was cloned into EcoRI site of the pAO815 to construct the pAO_D-PhgAT plasmid. The groEL and groES genes encoding the GroEL and GroES chaperonins were individually amplified from the pGro7 plasmid using the forward and reverse primers (FgroEL_GAP, RgroEL_GAP and FgroES_GAP, RgroES_GAP) containing EcoRI and XbaI 
sites for cloning separately into pGAPZ $B$ to yield the pGAPZ B_GroEL and pGAPZ B_GroES, respectively. The pGAPZ B_GroES plasmid was cut with BglII and BamHI and the resulting $1.2 \mathrm{~kb}$ of GroES expression cassette was ligated into the BamHI-digested pGAPZ B_GroEL to generate the pGAPZ B_GroEL_GroES. The combined expression cassette of GroEL and GroES was cloned into the BamHI-digested pAO815_D-PhgAT to create the pAO_DPhgAT_GAP_ELS [see Additional file 1]. The construction of pAO_D-PhgAT_AOX_ELS was done by a similar procedure except that the $g r o E L$ and $g r o E S$ genes were cloned into the pAO815, instead of the pGAPZ B, to place the chaperonin genes under the control of the $A O X 1$ promoter. (In the cloning of $d p g A$, groEL, groES genes into the pAO815, the pAO815 plasmid was cut with EcoRI. The dpgA, groEL, groES were amplified with primers (Table 3) that incorporated an EcoRI site at one end and a BsaI site at the other end of the PCR products. The BsaI digested end is compatible with the EcoRI overhang and can be ligated to the EcoRI site but after ligation the EcoRI recognition sequence was destroyed. Orientation of the inserted gene can be determined by double digestions of the recombinant plasmid with EcoRI and BamHI.) The pAO_D-PhgAT_GAP_ELS and pAO_D-PhgAT_AOX_ELS plasmids were each linearized with StuI and transformed into P. pastoris KM71. Transformants were selected on minimal dextrose (MD) without histidine plates. PCR analyses using gene-specific primers were done to confirm the presence of $\operatorname{dpgA}$, groEL and groES genes integrated in the $P$. pastoris chromosome.

\section{In vivo generation of $P$. pastoris KM71 containing multiple copies of $\operatorname{dpg} A$, groEL and groES genes}

The GroEL and GroES expression cassettes were PCR amplified from the pGAPZ B_GroEL_GroES using the forward and reverse primers F_ELS_PICZ and R_ELS_PICZ (Table 3) containing XhoI and NotI sites, respectively, for cloning into pPICZ_26S rDNA. The resulting pPICZ_26S rDNA_GAP_GroELS [see Additional file 2] was linearized with either $S a c$ I or SfoI for integration at the $5^{\prime} \mathrm{AOX} 1$ or $26 \mathrm{~S}$ rDNA locus, respectively, in the chromosome of the recombinant $P$. pastoris KM71 chromosomally harboring multiple copies of $d p g A$ gene previously generated by transforming the KM71 host with pPIC3.5K_DPhgAT. The transformants were first selected on YPD plates containing $25 \mu \mathrm{g} \mathrm{mL} \mathrm{m}^{-1}$ of zeocin. Subsequently, the resistant clones were re-streaked on YPD plates with higher concentration of zeocin $(100,500$, 1000, 2000 and $5000 \mu \mathrm{g} \mathrm{mL}^{-1}$ ) to select for clones having multiple copies of groEL and groES genes. The copy numbers of the genes integrated were determined by quantitative real-time PCR.

\section{Real-time PCR}

Quantitative real time-PCR was performed in duplicates using the QuantiTect SYBR Green PCR Kit (QIAGEN) in $20 \mu \mathrm{L}$ reaction mixture containing $2 \mathrm{ng}$ of genomic DNA and $0.5 \mu \mathrm{M}$ of each primer. The thermal cycling conditions started with $15 \mathrm{~min}$ at $95^{\circ} \mathrm{C}$ followed by 40 cycles of $30 \mathrm{~s}$ at $95^{\circ} \mathrm{C}, 30 \mathrm{~s}$ at $60^{\circ} \mathrm{C}$ and $45 \mathrm{~s}$ at $72^{\circ} \mathrm{C}$ (Rotor-Gene RG-3000, Corbett Research). After the amplification, a melting curve analysis with a temperature gradient of $0.1^{\circ} \mathrm{C} \mathrm{s}^{-1}$ from $65^{\circ} \mathrm{C}$ to $95^{\circ} \mathrm{C}$ was examined to exclude the amplification of nonspecific products. For correct determination of the starting copy quantity, the reference gene actin was quantified in parallel. The normalized copy number was calculated by relative quantification as described by Livak and Schmittgen [43] with the following formula; $n=2^{-\Delta \Delta C t}$ where $\Delta \Delta \mathrm{Ct}=(\mathrm{Ct}$ target sample $-\mathrm{Ct}$ reference sample $)-$ (Ct target calibrator - Ct reference calibrator). Ct was defined as the point at which the fluorescence level rose above the baseline. The P. pastoris KM71 chromosomally harboring single copy each of the $d p g A$, groEL, groES gene from the pAO_D-PhgAT_GAP_ELS plasmid was used as the calibrator.

\section{Expression of D-PhgAT and GroEL-ES in P. pastoris KM71}

Each constructed strain was grown in $200 \mathrm{~mL}$ of BMGY (1\% yeast extract, $2 \%$ peptone, $100 \mathrm{mM}$ potassium phosphate, $\mathrm{pH} 6.0,1.34 \% \mathrm{YNB}, 4 \times 10^{-5} \%$ biotin and $1 \%$ glycerol) medium contained in a $1000 \mathrm{~mL}$ shake flask with 3 extra deep side baffles and $38 \mathrm{~mm}$ DeLong neck (Bellco, Part no. 2543-01000) and incubated at $30^{\circ} \mathrm{C}$ and $200 \mathrm{rpm}$ shaking until the culture reached an $\mathrm{OD}_{600 \mathrm{~nm}}$ of 6 . Cells were harvested by centrifugation at $2000 \times \mathrm{g}$ for $5 \mathrm{~min}$ at room temperature. The cells were resuspended in $40 \mathrm{~mL}$ of BMMY (0.5\% methanol) medium to an $\mathrm{OD}_{600 \mathrm{~nm}}$ of 30 , transferred into a $500 \mathrm{~mL}$ shake flask with 3 extra deep side baffles and $38 \mathrm{~mm}$ DeLong neck (Bellco, Part no. 2543-00500) and incubated at the desired temperature to induce the expression of the recombinant D-PhgAT and GroEL-ES. At specified time point, the culture was harvested by centrifugation. For time course study of enzyme expression, methanol was added to the culture to a final concentration of $0.5 \%$ at every $24 \mathrm{~h}$ in addition to that at the beginning of the induction of gene expression. For viable cell count determination, culture samples were 10 -fold serially diluted with $100 \mathrm{mM}$ potassium phosphate, $\mathrm{pH} 6$, and $100 \mu \mathrm{L}$ aliquots of the $10^{-6}$ dilutions were plated on YPD agar. The plates were incubated at $30^{\circ} \mathrm{C}$ for $72 \mathrm{~h}$ before viable cell counts were manually scored. Determinations were done in triplicates.

In the experiments with chemical additives, when the BMGY culture reached an $\mathrm{OD}_{600 \mathrm{~nm}}$ of 6 , sorbitol 
was added to a final concentration of $0.5 \mathrm{M}$ and incubated at the desired temperature for $1 \mathrm{~h}$. Cells were pelleted, resuspended in BMMY plus 0.5 M sorbitol, and the incubation was continued for the specified period before the cells were harvested and analyzed. When benzyl alcohol was used as an additive, the BMGY culture at the $\mathrm{OD}_{600 \mathrm{~nm}}$ of 6 was added with benzyl alcohol to a final concentration of $0.4 \mathrm{mM}$ and incubated at the desired temperature for $1 \mathrm{~h}$. Cells were pelleted, resuspended in BMMY plus 0.4 $\mathrm{mM}$ benzyl alcohol, and incubated at the desired temperature with shaking for the specified period before the cells were harvested and analyzed.

\section{Preparation of cell-free extracts}

Protein extraction was accomplished by using a French Press (FA-081A, Thermo Electron Corp.). Cell pellets were washed once and resuspended in chilled lysis buffer (50 mM sodium phosphate, $\mathrm{pH}$ 7.4, $1 \mathrm{mM}$ PMSF, $1 \mathrm{mM}$ EDTA and 5\% glycerol) with the ratio of cell wet weight to buffer volume of 1:4. Each sample was subjected to 16000 psi cell pressure for 4 passes. The cell lysate was centrifuged at $12000 \mathrm{x} \mathrm{g}$ for $10 \mathrm{~min}$ at $4^{\circ} \mathrm{C}$ and the supernatant was collected for determining the D-PhgAT activity.

Protein concentration was determined using the Bradford dye-binding protein assay (Bio-Rad) with bovine serum albumin as a standard.

\section{Purification of the 6xHis-tagged D-PhgAT using immobilized cobalt affinity chromatography}

After cultivation, cell-free extract was prepared as described above using lysis buffer without EDTA. Protein purification was performed using an AKTAprime protein chromatography system (GE Healthcare). The BD TALON ${ }^{\mathrm{TM}}$ (BD Biosciences) metal affinity resin was packed in a chromatographic column (Tricorn 10/150, GE Healthcare) to a bed volume of $9 \mathrm{~mL}$. The column was pre-equilibrated with 10 column volumes of binding buffer (50 mM sodium phosphate, $\mathrm{pH}$ 7.4, containing $10 \mu \mathrm{M}$ PLP and $0.1 \mathrm{M} \mathrm{NaCl}$ ). A $10 \mathrm{~mL}$ aliquot of the cell-free extract sample was applied onto the column by means of an injection loop at a flow rate of $1 \mathrm{~mL} \cdot \mathrm{min}^{-1}$ (linear flow rate $=76.4 \mathrm{~cm} \cdot \mathrm{h}^{-1}$ ). The column was washed with 5 column volumes of the same buffer to remove the unbound materials. The proteins were eluted with a linear gradient of 0-60 mM imidazole contained in the binding buffer for 15 column volumes at the same flow rate. Eluted proteins were collected in $3 \mathrm{~mL}$ fractions. Fractions containing D-PhgAT were located by D-PhgAT activity assay and the active fractions were pooled. By means of an Amicon Ultra Centrifugal Filter Device (Millipore) with a $50 \mathrm{kDa}$ cut-off membrane, the pooled active fractions were concentrated and washed 3 times with $20 \mathrm{~mL}$ of buffer (50 mM sodium phosphate, $\mathrm{pH}$ 7.4, $1 \mathrm{mM}$ PMSF, $1 \mathrm{mM}$
EDTA and $5 \%$ glycerol). The purity of the enzyme was assessed by SDS-PAGE.

\section{Determination of D-phenylglycine aminotransferase activity}

The D-PhgAT activity assay was performed using the published method [44] with some modifications. In a $1 \mathrm{~mL}$ reaction, $20 \mu \mathrm{L}$ of soluble enzyme fraction was mixed into $980 \mu \mathrm{L}$ of reaction mixture containing $100 \mathrm{mM} \mathrm{CAPSO}$, $\mathrm{pH}$ 9.0, $10 \mathrm{mM}$ D-4-hydroxyphenylglycine, $10 \mathrm{mM}$ $\alpha$-ketoglutaric acid, $25 \mu \mathrm{M}$ EDTA and $25 \mu \mathrm{M}$ PLP. The rate of 4-hydroxybenzoylformate formation was measured as a function of time by monitoring the increase in the absorbance at $340 \mathrm{~nm}$ using a spectrophotometer (Biospec1601, Shimadzu Corp., Japan).

\section{SDS-polyacrylamide gel electrophoresis}

Total cellular proteins were analyzed by preparing the samples as followed [45]. A $3 \mathrm{mg}$ wet weight of cell pellet was washed once and resuspended in $0.3 \mathrm{~mL}$ of distilled water, then an equal volume of $0.2 \mathrm{M} \mathrm{NaOH}$ was added. After $5 \mathrm{~min}$ incubation at room temperature, the cells were collected and the supernatant was carefully removed. A $70 \mu \mathrm{L}$ volume of SDS sample buffer was added to each pellet and mixed by repeatedly pipetting. The samples were boiled for $3 \mathrm{~min}$ to solubilize the cell contents, and centrifuged briefly. A $15 \mu \mathrm{L}$ of cell extract in the sample buffer of each sample was subjected to SDS-polyacrylamide gel electrophoresis in $4 \%$ stacking- and $12 \%$ separating gel (MiniProtein II Dual Slab Cell, Bio-Rad) at $150 \mathrm{~V}$ for $1 \mathrm{~h}$ and the gel was stained with Coomassie Brilliant Blue.

To distinguish between soluble and insoluble proteins, the cell lysate obtained after cell disruption by French Press was centrifuged at $12000 \mathrm{xg}$ for $10 \mathrm{~min}$ at $4^{\circ} \mathrm{C}$. The supernatant containing soluble proteins was carefully separated from the pellet containing insoluble proteins. Lysis buffer equal to the volume of the supernatant removed was added to dissolve the pellets. The protein samples from the soluble and insoluble fractions were mixed with SDS-sample buffer before boiling for $10 \mathrm{~min}$, and then centrifuged briefly. For each sample, 30 microgram of protein was loaded into the gel.

\section{Additional files}

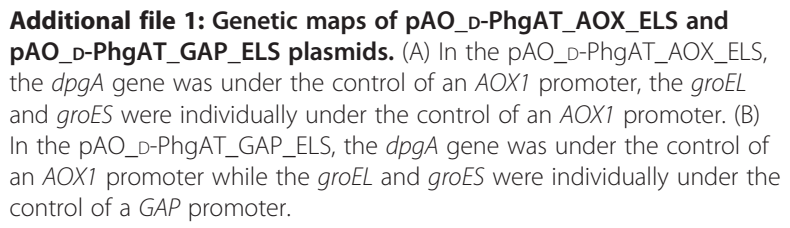

Additional file 2: Genetic map of the pPICZ_26S rDNA_GAP_GroELS plasmid. 
Additional file 3: DNA sequence alignment comparing the wild-type Pseudomonas stutzeri $d p g A$ gene with the synthetic $d p g A$ gene codon-optimized for expression in $P$. pastoris. The codonoptimized dpgA gene was modified at the C-terminus with (His) $)_{6}$-Cys coding sequence before the stop codon to facilitate protein purification by immobilized ion affinity chromatography and to serve as a site specific for enzyme immobilization at the terminal Cys.

\section{Competing interests}

The authors declare that they have no competing interests.

\section{Authors' contributions}

$\mathrm{KJ}$ designed and performed the experiments, analyzed data and drafted the manuscript. PL participated in planning the experiments and interpretation of results. VM criticized and gave suggestions on the results. SW conceived the study, followed up, supervised the research work and validated all data. $\mathrm{KJ}$ and SW wrote the paper. All authors read and approved the final manuscript.

\section{Acknowledgements}

This research was financially supported by the Thailand Research Fund Grant No. RSA4780014 to SW and the Royal Golden Jubilee Ph.D. Program (Grant No. PHD/0007/2549) to KJ, and the Center of Excellence for the Agricultural Biotechnology, Science and Technology, Postgraduate Education and Research Development Office (PERDO), Commission on Higher Education, Ministry of Education, Thailand. We are also grateful to Prof. Watanalai Panbangred (Dept. of Biotechnology, Mahidol University) for providing the pPICZ_26S rDNA plasmid.

\section{Author details}

${ }^{1}$ Department of Biotechnology, Faculty of Science, Mahidol University, Rama 6 Road, Bangkok 10400, Thailand. ${ }^{2}$ Department of Microbiology, Faculty of Science, Mahidol University, Rama 6 Road, Bangkok 10400, Thailand. ${ }^{3}$ Center of Excellent for Agricultural Biotechnology: (AG-BIO/PERDO-CHE), Bangkok, Thailand.

Received: 6 September 2011 Accepted: 26 March 2012 Published: 19 April 2012

\section{References}

1. Wiyakrutta S, Meevootisom V: A stereo-inverting D-phenylglycine aminotransferase from Pseudomonas stutzeri ST-201: purification, characterization and application for D-phenylglycine synthesis. J Biotechnol 1997, 55(3):193-203.

2. Leuchtenberger W, Huthmacher K, Drauz K: Biotechnological production of amino acids and derivatives: current status and prospects. Appl Microbiol Biotechnol 2005, 69:1-8.

3. Soda K, Esaki N: Pyridoxal enzymes acting on D-amino acids. Pure Appl Chem 1994, 66:709-714.

4. Coulter-Mackie MB, Lian Q, Wong SG: Overexpression of human alanine: glyoxylate aminotransferase in Escherichia coli: renaturation from guanidine- $\mathrm{HCl}$ and affinity for pyridoxal phosphate co-factor. Protein Expr Purif 2005, 41(1):18-26.

5. Cregg JM, Cereghino JL, Shi J, Higgins DR: Recombinant protein expression in Pichia pastoris. Mol Biotechnol 2000, 16:23-52.

6. Macauley-Patrick S, Fazenda ML, McNeil B, Harvey LM: Heterologous protein production using the Pichia pastoris expression system. Yeast 2005, 22:249-270.

7. Gellissen G: Heterologous protein production in methylotrophic yeasts. Appl Microbiol Biotechnol 2000, 54:714-750.

8. Hong F, Meinander NQ, Jonsson L: Fermentation strategies for improved heterologous expression of laccase in Pichia pastoris. Biotechnol Bioeng 2002, 79:438-449.

9. Li Z, Xiong F, Lin Q, de Anjou M, Daugulis AJ, Yang DSC, Hew CL: Low-temperature increases the yield of biologically active herring antifreeze protein in Pichia pastoris. Protein Expr Purif 2001, 21:438-445.

10. Shi X, Karkut T, Chamankhah M, Alting-Mees M, Hemmingsen SM, Hegedus D: Optimal conditions for the expression of a single-chain antibody (scFv) gene in Pichia pastoris. Protein Expr Purif 2003, 28:321-330.
11. Ramon R, Ferrer P, Valero F: Sorbitol co-feeding reduces metabolic burden caused by the overexpression of a Rhizopus oryzae lipase in Pichia pastoris. J Biotechnol 2007, 130:39-46.

12. Loewen MC, Liu X, Davies PL, Daugulis AJ: Biosynthetic production of type II fish antifreeze protein: fermentation by Pichia pastoris. Appl Microbiol Biotechnol 1997, 48:480-486.

13. Li P, Anumanthan A, Gao X-G, llangovan K, Suzara W: Expression of recombinant proteins in Pichia pastoris. Appl Biochem Biotechnol 2007, 142:105-124.

14. Hartner FS, Ruth C, Langenegger D, Johnson SN, Hyka P, Lin-Cereghino GP, LinCereghino J, Kovar K, Cregg JM, Glieder A: Promoter library designed for finetuned gene expression in Pichia pastoris. Nucleic Acids Res 2008, 36:e76.

15. Renugopalakrishnan V, Garduno-Juarez R, Narasimhan G, Verma CS, Wei X, Li P: Rational design of thermally stable proteins: relevance to biotechnology. J Nanosci Nanotechnol 2005, 5:1759-1767.

16. Trevino SR, Martin Scholtz J, Nick Pace C: Measuring and increasing protein solubility. J Pharm Sci 2008, 97:4155-4166.

17. Roodveldt C, Aharoni A, Tawfik DS: Directed evolution of proteins for heterologous expression and stability. Curr Opin Struct Biol 2005, 15:50-56.

18. Waldo GS: Genetic screens and directed evolution for protein solubility. Curr Opin Chem Biol 2003, 7:33-38.

19. Rotticci-Mulder JC, Gustavsson M, Holmquist M, Hult K, Martinelle M: Expression in Pichia pastoris of Candida antarctica lipase B and lipase B fused to a cellulose-binding domain. Protein Expr Purif 2001, 21:386-392.

20. Yang D, Peng $M$, Yang $H$, Yang Q, Xu J: Expression, purification and characterization of Gloydius shedaoensis venom gloshedobin as Hsp70 fusion protein in Pichia pastoris. Protein Expr Purif 2009, 66:138-142.

21. Li Z, Leung W, Yon A, Nguyen J, Perez VC, Vu J, Giang W, Luong LT, Phan T, Salazar KA, Gomez SR, Au C, Xiang F, Thomas DW, Franz AH, Lin-Cereghino J, Lin-Cereghino GP: Secretion and proteolysis of heterologous proteins fused to the Escherichia coli maltose binding protein in Pichia pastoris. Protein Expr Purif 2010, 72:113-124.

22. Esposito D, Chatterjee DK: Enhancement of soluble protein expression through the use of fusion tags. Curr Opin Biotechnol 2006, 17:353-358.

23. Gasser B, Saloheimo M, Rinas U, Dargosits M, Rodriguez-Carmona E, Baumann K, Giuliani M, Parrilli E, Branduardi P, Lang C, Porro D, Ferrer P, Tutino ML, Mattanovich D, Villaverde A: Protein folding and conformational stress in microbial cells producing recombinant proteins: a host comparative overview. Microb Cell Fact 2008, 7:11

24. Young JC, Agashe VR, Siegers K, Hartl FU: Pathways of chaperonemediated protein folding in the cytosol. Nat Rev Mol Cell Biol 2004 5:781-791.

25. Damasceno LM, Anderson KA, Ritter G, Cregg JM, Old LJ, Batt CA: Cooverexpression of chaperones for enhanced secretion of a singlechain antibody fragment in Pichia pastoris. Appl Microbiol Biotechnol 2007, 74:381-389.

26. Zhang W, Zhao HL, Xue C, Xiong XH, Yao XQ, Li XY, Chen HP, Liu ZM: Enhanced secretion of heterologous proteins in Pichia pastoris following overexpression of Saccharomyces cerevisiae chaperone proteins. Biotechnol Prog 2006, 22:1090-1095.

27. Gustafsson C, Govindarajan S, Minshull J: Codon bias and heterologous protein expression. Trends Biotechnol 2004, 22:346-353.

28. Daly R, Hearn MT: Expression of heterologous proteins in Pichia pastoris: a useful experimental tool in protein engineering and production. $J \mathrm{Mol}$ Recognit 2005, 18:119-138.

29. Vassileva A, Chugh DA, Swaminathan S, Khanna N: Expression of hepatitis $B$ surface antigen in the methylotrophic yeast Pichia pastoris using the GAP promoter. J Biotechnol 2001, 88(1):21-35.

30. Mansur M, Cabello C, Hernandez L, Pais J, Varas L, Valdes J, Terrero Y, Hidalgo A, Plana L, Besada V, Garcia L, Lamazares E, Castellanos L, Martinez E: Multiple gene copy number enhances insulin precursor secretion in the yeast Pichia pastoris. Biotechnol Lett 2005, 27:339-345.

31. Sunga AJ, Tolstorukov I, Cregg JM: Posttransformational vector amplification in the yeast Pichia pastoris. FEMS Yeast Res 2008, 8:870-876.

32. de Marco A, Vigh L, Diamant S, Goloubinoff P: Native folding of aggregation-prone recombinant proteins in Escherichia coli by osmolytes, plasmid- or benzyl alcohol-overexpressed molecular chaperones. Cell Stress Chaperones 2005, 10:329-339.

33. Zhang $W$, Inan $M$, Meagher $M$ : Fermentation strategies for recombinant protein expression in the methylotrophic yeast Pichia pastoris. Biotechnol Bioprocess Eng 2000, 5(4):275-287. 
34. Brierley RA, Bussineau C, Kosson R, Melton A, Siegel RS: Fermentation development of recombinant Pichia pastoris expressing the heterologous gene: bovine lysozyme. Ann N Y Acad Sci 1990, 589:350-362.

35. Cregg JM, Vedvick TS, Raschke WC: Recent advances in the expression of foreign genes in Pichia pastoris. Biotechnology (N Y) 1993, 11(8):905-910.

36. Diamant $S$, Eliahu N, Rosenthal D, Goloubinoff P: Chemical chaperones regulate molecular chaperones in vitro and in cells under combined salt and heat stresses. J Biol Chem 2001, 276(43):39586-39591.

37. Oganesyan N, Ankoudinova I, Kim SH, Kim R: Effect of osmotic stress and heat shock in recombinant protein overexpression and crystallization. Protein Expr Purif 2007, 52(2):280-285.

38. Hohmann S: Osmotic stress signaling and osmoadaptation in yeasts. Microbiol Mol Biol Rev 2002, 66(2):300-372.

39. Mattanovich D, Gasser B, Hohenblum H, Sauer M: Stress in recombinant protein producing yeasts. J Biotechnol 2004, 113(1-3):121-135.

40. Hartner FS, Glieder A: Regulation of methanol utilisation pathway genes in yeasts. Microb Cell Fact 2006, 5:39.

41. Moskvina $\mathrm{E}$, Imre EM, Ruis $\mathrm{H}$ : Stress factors acting at the level of the plasma membrane induce transcription via the stress response element (STRE) of the yeast Saccharomyces cerevisiae. Mol Microbiol 1999, 32 (6):1263-1272.

42. Kongsaeree P, Samanchart C, Laowanapiban P, Wiyakrutta S, Meevootisom V: Crystallization and preliminary X-ray crystallographic analysis of D-phenylglycine aminotransferase from Pseudomonas stutzeri ST201. Acta Crystallographica 2003, 59(Pt 5):953-954.

43. Livak KJ, Schmittgen TD: analysis of relative gene expression data using real-time quantitative PCR and the $2^{-\Delta \Delta C T}$ method. Methods 2001, 25 (4):402-408.

44. Khampha W, Wiyakrutta S, Meevootisom V: Spectrophotometric enzymatic cycling method using L-glutamate dehydrogenase and D-phenylglycine aminotransferase for determination of L-glutamate in foods. Anal Chim Acta 2004, 520(1-2):133-139.

45. Matsuo Y, Asakawa K, Toda T, Katayama S: A rapid method for protein extraction from fission yeast. Biosci Biotechnol Biochem 2006, 70(8): 1992-1994.

\section{doi:10.1186/1475-2859-11-47}

Cite this article as: Jariyachawalid et al: Effective enhancement of Pseudomonas stutzeri

D-phenylglycine aminotransferase functional expression in Pichia pastoris by co-expressing Escherichia coli GroEL-GroES. Microbial Cell Factories 2012 11:47.

\section{Submit your next manuscript to BioMed Central and take full advantage of:}

- Convenient online submission

- Thorough peer review

- No space constraints or color figure charges

- Immediate publication on acceptance

- Inclusion in PubMed, CAS, Scopus and Google Scholar

- Research which is freely available for redistribution 